\title{
The prognostic significance of normal technetium-99m MIBI myocardial perfusion spect imaging over a four-year follow-up period
}

\author{
Authors: Hans J Neethling MB,ChB, MMed (Int Med) \\ Ben B van Heerden MB,ChB MSc MMed (Int Med), \\ Johannes F Klopper MB,ChB, MMed (Int Med), MD (Nuc Med) \\ Annare Ellmann MB,ChB, MSc, MMed (Nuc Med)
}

Stellenbosch University and Tygerberg Academic Hospital

Address for correspondence:

Prof Annare Ellmann

Department of Medical Imaging and Clinical Oncology

Tygerberg Academic Hospital

Tygerberg

7505 South Africa

Email:

ael@sun.ac.za

ABSTRACT A normal Tc-99m MIBI myocardial perfusion study has previously been shown to indicate a benign prognosis. Our aim was to determine the longer term prognosis of a normal study in our patient population.

Methods: A retrospective evaluation of 209 patients with a normal Tc-99m MIBI study was performed. Follow-up data was obtained in 157 patients, with complete follow-up in I2I (mean follow-up period of 56 months). In 36 patients only partial follow-up was possible (32 months follow-up). No follow-up data, except for the possible registration of deaths, could be obtained in 52. Patients were evaluated for the occurrence of primary or secondary cardiac events.

Results: The study group had a moderate pre-test probability for coronary artery disease $(48+30.7 \%)$. Two possible cardiac deaths occurred (cardiac death rate of $0.95 \%$ ). No primary events occurred in the group with complete follow-up, but 6 secondary events were recorded (cardiac event rate of $4.9 \%$ ). No primary or secondary events occurred in the partial follow-up group during the follow-up period. The incidence of secondary or non-fatal primary events in this group for the period after they were lost to follow-up or in the group with no follow-up could not be ascertained. There was, however, no statistically significant difference between these groups regarding age, pre-test probability and exercise parameters.

Conclusion: Similar to the findings with TI-20I, our study indicates a favourable longer term prognosis after a normal Tc-99m MIBI study.

Key words: Myocardial perfusion imaging; Prognostic significance of normal myocardial perfusion imaging; Tc-99m MIBI; SPECT myocardial perfusion imaging; Long-term follow-up

\section{INTRODUCTION}

Thallium-20I (TI-20I) has for many years been the radiotracer of choice for the scintigraphic evaluation of myocardial perfusion, but technetium-99m (Tc-99m) methoxy-isobutylisonitrile (MIBI) was shown to be a reliable alternative radiopharmaceutical for detecting coronary artery disease (CAD) and is preferable to TI-20I due to the better physical characteristics of the Tc-99m label for imaging. The accuracy of the two techniques to detect CAD has also been shown to be equal. ${ }^{(I-14)}$ Advantages of using the Tc-99m agent include better image quality and the ability to simultaneously assess left ventricular function. ${ }^{(5,6)}$

The prognostic significance of a normal stress-redistribution TI-20I myocardial perfusion study in patients with known or suspected CAD is well documented, showing a benign outcome in such patients over the short- and long-term, with an overall cardiac event rate of less than I\% per year. ${ }^{(15-31)}$

Previous studies have evaluated the prognostic value of a normal Tc-99m MIBI stress study over a period of 6-16 months using planar imaging, ${ }^{(32)}$ over one year using single photon emission computed tomography (SPECT) or planar imaging, ${ }^{(33)}$ over 19.6 months using dual isotope TI-20I (rest) and Tc-99m MIBI (exercise) SPECT, ${ }^{(34)}$ after dipyridamole Tc-99m sestamibi imaging(35) and over $22 \pm 13$ months after dobutamine-atropine stress. ${ }^{(36)}$ All these studies confirmed a benign short-term outcome in these patients with an overall cardiac event rate of less than $1 \%$ per year.

Longer follow-up studies were also reported with Tc-99m MIBI and Tc-99m tetrofosmin. ${ }^{(37-40)}$ Most of these studies reported their experience with all patients referred for myocardial perfusion imaging. However, Yang et al. specifically reported on 90 patients with normal exercise myocardial perfusion imaging studies, but with angiographic coronary artery disease. ${ }^{(41)}$ All these reports confirmed an overall cardiac event rate in patients with normal myocardial perfusion imaging studies of less than $1 \%$ per year.

The aim of our study was to determine whether the benign prognostic significance of a normal Tc-99m MIBI stress-rest myocardial perfusion SPECT study over a longer term could also be proven in our patient population.

\section{METHODS}

\section{Patients}

We performed a retrospective analysis of the outcome in 209 consecutive patients with known or suspected CAD, reported to have a normal Tc-99m MIBI exercise-rest myocardial perfusion SPECT study 
performed over a three-year period. No follow-up data could be obtained in 52 (24.8\%) of these patients. Of the remaining I 57 patients, follow-up was complete in 121. Only partial follow-up was possible in 36 patients, i.e. follow-up data could only be obtained for a certain period after the MIBI study was performed, whereafter the patients were lost to further follow-up.

The pre-test probability for CAD was determined by using Bayes' theorem of conditional probability of age, sex and presenting symptom. ${ }^{(42)}$ Presenting symptoms were: no symptoms, typical angina pectoris, and atypical (non-anginal) chest pain. ${ }^{(43)}$

\section{Myocardial perfusion imaging}

A same day exercise-rest protocol was utilised in all patients. Exercise was performed on a treadmill according to the Bruce protocol. An intravenous injection of $260 \mathrm{MBq}(7 \mathrm{mCi}) T \mathrm{c}-99 \mathrm{~m} \mathrm{MIBI}$ was administered when the patient reached the target heart rate or other accepted endpoint. Myocardial perfusion SPECT imaging commenced $30 \mathrm{~min}$ after injection. The rest injection of $740 \mathrm{MBq}(20 \mathrm{mCi})$ was administered 3 hours later and SPECT imaging performed I hour after injection.

SPECT data were acquired for both the exercise and rest studies, using a single detector rotating gamma camera equipped with a low energy all purpose collimator. A 20\% energy window, centred around I $40 \mathrm{keV}$ was used. Thirty images were acquired into $64 \times 64$ matrix frames in the step-and-shoot mode at 40 s per step. A $180^{\circ}$ elliptical orbit from $45^{\circ}$ right anterior oblique to $45^{\circ}$ left posterior oblique was used.

Transaxial slices of the myocardium were reconstructed for both exercise and rest studies, using a Hanning filter with cut-off at 0,73 cycles/cm. Horizontal and vertical long axis slices as well as short axis slices were subsequently generated and displayed according to the recommendations of the American College of Cardiology / American Heart Association / Society of Nuclear Medicine (ACC/AHA/SNM) ${ }^{\left({ }^{(4)}\right.}$

Studies were reported by three experienced Nuclear Medicine physicians and were considered to be normal when the exercise study showed only homogenous distribution of the radiopharmaceutical in the left ventricular myocardium without any perfusion defects. Patients were included in the study group if the final report sent to the referring physician was reported as being normal.

\section{Follow-up}

Follow-up data were obtained from hospital records and/or telephone interviews with the patients, patients' relatives or attending general practitioners. In the patients where no follow-up information could be obtained, or where the patients were lost to follow-up (partial followup), the Registrar of Deaths of the South African Department of the Interior was approached to obtain information regarding the number and cause of deaths that occurred in these patients.
Patients were evaluated for the occurrence of: 1) primary cardiac events (cardiac death or non-fatal myocardial infarction); 2) secondary cardiac events (recurrent chest pain requiring revascularisation by either percutaneous transluminal coronary angioplasty (PTCA) or coronary artery bypass grafting (CABG)); 3) no cardiac events during the follow-up period. Cardiac catheterisation per se was not considered to be a cardiac event

\section{Statistical analysis}

Where applicable, values are presented as the mean value \pm one standard deviation (SD) of the mean, with the range given in brackets.

Single factor analysis of variance (ANOVA) was used to test for significant differences between the groups with complete, partial or no follow-up. A p-value of less than 0.05 was considered a significant difference.

\section{RESULTS}

\section{Presenting features}

The biographical data of the patients are summarised in Table I.

\section{TABLE I: Patient data}

\begin{tabular}{lcccc}
\hline \hline Number of patients & $\begin{array}{c}\text { Complete } \\
\text { follow-up }\end{array}$ & $\begin{array}{c}\text { Partial } \\
\text { follow-up }\end{array}$ & $\begin{array}{c}\text { No } \\
\text { follow-up }\end{array}$ \\
Male / Female & 121 & 36 & 52 \\
\hline Age (years) * & $63 / 58$ & $15 / 21$ & $32 / 20$ \\
& $52.5 \pm 11.2$ & $52.1 \pm 10.9$ & $48.3 \pm 9.2$ \\
& $(31-72)$ & $(34-70)$ & $(30-67)$ \\
\hline Pre-test probability of CAD (\%)* & $48.2 \pm 30.4$ & $51.3 \pm 33.9$ & $45.2 \pm 29.6$ \\
& $(2.8-91.5)$ & $(0.8-91.2)$ & $(0.8-93.5)$ \\
\hline Mean follow-up period (months) & $55.6 \pm 11.2$ & $32.3 \pm 14.6$ & 0 \\
& $(9-78)$ & $(4-59)$ & \\
\hline
\end{tabular}

Where applicable, values are presented as mean \pm I SD followed by the range in brackets *No statistically significant difference (ANOVA) between groups

ANOVA showed no statistically significant difference in mean age $(p=0.06)$ between the groups with complete, partial or no follow-up.

Forty-three of the 121 patients (36\%) with complete follow-up presented with typical anginal chest pain, 65 (53\%) had atypical chest pain, and 13 (1 1\%) were asymptomatic. Of the 36 patients in whom only partial follow-up data were available, I 4 (39\%) had typical anginal chest pain at presentation, and 22 (61\%) presented with atypical chest pain. In the group with no follow-up information available, 15 of the 52 patients (29\%) presented with typical anginal pain, and 32 (61\%) with atypical chest pain. Four patients (8\%) were asymptomatic and in one (2\%) the presenting symptom was unknown. The percentage of patients in each group presenting with typical angina and atypical angina, and with no symptoms is graphically represented in Figure I. 
THE PROGNOSTIC

SIGNIFICANCE OF NORMAL

TECHNETIUM-99M MIBI

MYOCARDIAL PERFUSION

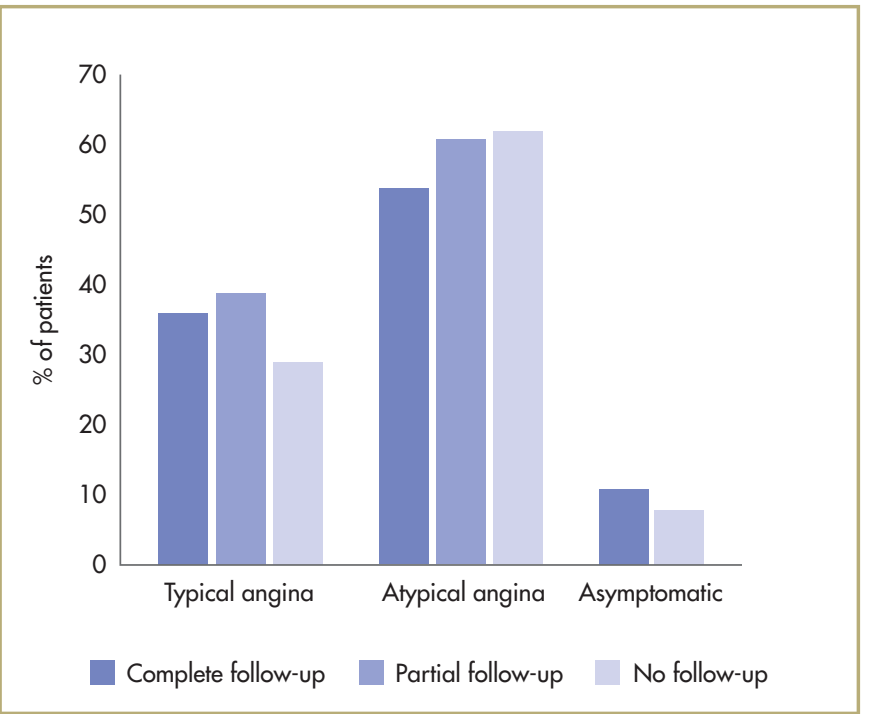

FIGURE 1: Presenting symptoms of the patients in the three different follow-up categories

The mean pre-test probability for CAD in our study population was 48 $\pm 30.7 \%$ (0.8\%-94.3\%). ANOVA again showed no statistically significant difference $(p=0.65)$ in the mean pre-test probability between the group in whom follow-up was complete and the groups with partial follow-up or no follow-up.

Twenty-eight of the 209 patients (13.4\%) (14 with complete follow-up information) underwent coronary angiography for their symptoms prior to the Tc-99m MIBI study. Of these, II had a normal coronary angiogram. Coronary artery disease was present in the remaining 17 patients (8.1\% of the study population), of whom II are known to have had a revascularisation procedure (PTCA or CABG) performed prior to the MIBI study. No follow-up information was available in I of these 17 patients. Five of the 17 patients (2.4\% of the study population) had significant (> 50\%) coronary arterial narrowing in one or more coronary arteries, but had no revascularisation procedure performed during the follow-up period, although two of these patients were lost to follow-up after follow-up periods of respectively 48 and 45 months. One of these two patients subsequently died, presumably of a myocardial infarction, as will be discussed later. The data of the 5 patients with significant CAD and no revascularisation are summarised in Table 2.

TABLE 2: Patients with significant $C A D$ and no revascularisation

\begin{tabular}{|l|c|c|c|c|}
\hline Patient & Sex & Age & $\begin{array}{c}\text { Follow-up period } \\
\text { (months) }\end{array}$ & $\begin{array}{c}\text { Pre-test probability } \\
\text { for CAD }\end{array}$ \\
\hline |* & F & 70 & 48 & 90.6 \\
\hline 2 & M & 47 & 78 & 87.3 \\
\hline 3 & M & 54 & 66 & 92.0 \\
\hline 4 & M & 52 & 44 & 92.0 \\
\hline 5 & F & 65 & 45 & 90.6 \\
\hline
\end{tabular}

*Patient died 7 I months after MIBI study (see text)

$M=$ male; $F=$ female $C A D=$ coronary artery disease

\section{Tc-99m MIBI myocardial perfusion scintigraphy}

The exercise data of the study group are summarised in Table III. ANOVA showed no statistically significant difference $(p>0.05)$ in any of the exercise parameters between the groups in which complete follow-up information was available and either only partial or no followup information was available.

\section{TABLE 3: Tc-99m MIBI stress data}

\begin{tabular}{|c|c|c|c|}
\hline & $\begin{array}{l}\text { Complete } \\
\text { follow-up }\end{array}$ & $\begin{array}{c}\text { Partial } \\
\text { follow-up }\end{array}$ & $\begin{array}{c}\text { No } \\
\text { follow-up }\end{array}$ \\
\hline Baseline heart rate / $\mathrm{min}$ & $\begin{array}{c}81 \pm 16 \\
(43-126)\end{array}$ & $\begin{array}{c}80 \pm 13 \\
(54-107)\end{array}$ & $\begin{array}{c}82 \pm 13 \\
(58-115)\end{array}$ \\
\hline Peak heart rate / min & $\begin{array}{c}162 \pm 13 \\
(108-187)\end{array}$ & $\begin{array}{c}166 \pm 9 \\
(138-179)\end{array}$ & $\begin{array}{c}164 \pm 12 \\
(122-178)\end{array}$ \\
\hline$\%$ of target heart rate & $\begin{array}{c}98 \pm 5 \\
(81-106)\end{array}$ & $\begin{array}{c}99 \pm 4 \\
(85-106)\end{array}$ & $\begin{array}{c}98 \pm 6 \\
(74-100)\end{array}$ \\
\hline Baseline systolic BP ( $\mathrm{mm} \mathrm{Hg}$ ) & $\begin{array}{c}138 \pm 20 \\
(90-200)\end{array}$ & $\begin{array}{c}128 \pm 15 \\
(100-160)\end{array}$ & $\begin{array}{c}138 \pm 24 \\
(90-200)\end{array}$ \\
\hline Baseline diastolic BP ( $\mathrm{mm} \mathrm{Hg}$ ) & $\begin{array}{c}89 \pm 10 \\
(60-110)\end{array}$ & $\begin{array}{c}88 \pm 8 \\
(70-100)\end{array}$ & $\begin{array}{c}91 \pm 12 \\
(60-110)\end{array}$ \\
\hline Peak systolic BP (mm Hg) & $\begin{array}{c}170 \pm 24 \\
(110-230)\end{array}$ & $\begin{array}{c}165 \pm 28 \\
(120-210)\end{array}$ & $\begin{array}{c}176 \pm 32 \\
(130-245)\end{array}$ \\
\hline Peak diastolic BP ( $(\mathrm{mm} \mathrm{Hg})$ & $\begin{array}{c}90 \pm 12 \\
(60-120)\end{array}$ & $\begin{array}{c}94 \pm 11 \\
(70-115)\end{array}$ & $\begin{array}{c}93 \pm 15 \\
(60-120)\end{array}$ \\
\hline
\end{tabular}

$B P=$ blood pressure

No statistically significant difference (ANOVA) was found in any of the exercise parameters between groups

\section{Follow-up period}

The mean follow-up period for the 157 patients in whom follow-up data (complete or partial) could be obtained was $50.3 \pm 15.5$ months ranging from 4 - 78 months. The mean follow-up period for the 121 patients with complete follow-up was $55.6 \pm 11.2$ months (range 9 78 months) and was $32.3 \pm 14.6$ months (range 4 - 59 months) for the 36 patients with partial follow-up. Figure 2 shows the number of patients involved in each 12-month follow-up period.

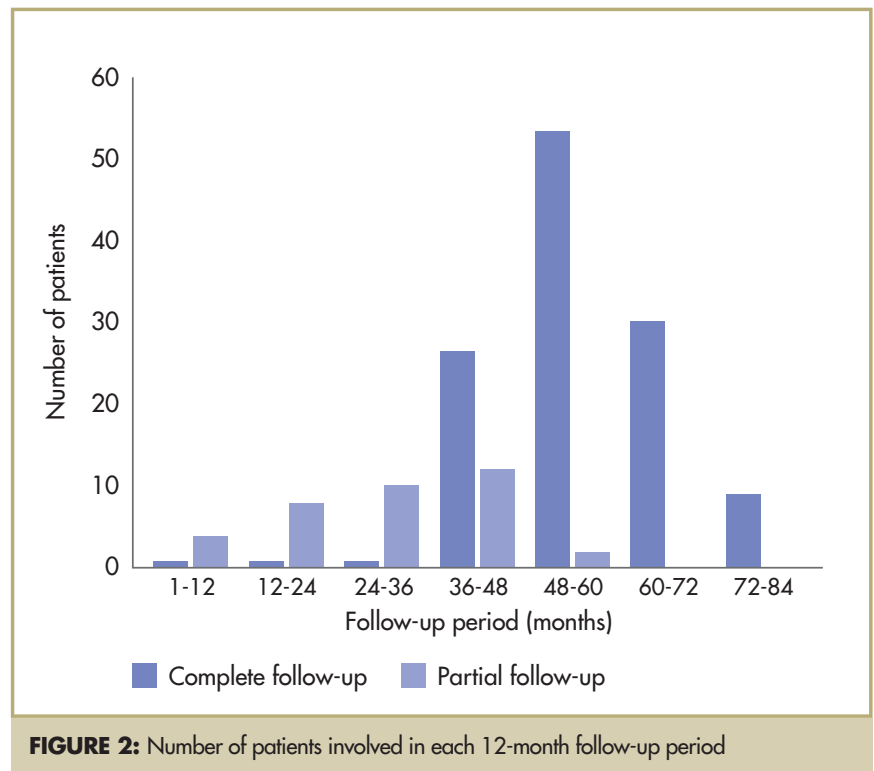


The main reasons for inability to obtain follow-up data were inaccurate hospital records (wrong telephone number and/or address), the fact that patients were no longer living at the available address and the unavailability of both an address and telephone number.

\section{Cardiac events}

Primary cardiac events:

None of the patients in whom complete follow-up information could be obtained, developed a cardiac death or non-fatal myocardial infarction during the follow-up period. Information obtained from the Registrar of Deaths showed that 2 patients for whom only partial or no follow-up information could be obtained, might have died from CAD. The cause of death in one patient was given as "myocardial infarction" on the death certificate. This patient died 7I months after the MIBI study. Follow-up information was available for the first 48 months after the MIBI study. This patient had coronary angiography performed prior to the MIBI study, which showed a $70 \%$ proximal left anterior descending artery lesion. No revascularisation procedure was performed. A followup coronary angiogram two years later failed to show any significant coronary artery lesions. In the other patient, who died 6 weeks after the MIBI study, the cause of death was given as "ischemic heart disease". Assuming that both these deaths were truly caused by CAD, the cardiac death rate in our study group was $0.95 \%$ during the whole follow-up period.

\section{Secondary cardiac events:}

Six of the 121 patients (4.9\%) in whom follow-up was complete, had recurrent chest pain requiring coronary angiography followed by revascularisation. Of these, only I patient (0.8\%) developed a cardiac event during the first year after the Tc-99m MIBI study. Three cardiac events (2.5\%) occurred during the first two years and 4 (3.3\%) during the first three years. The annual cardiac event rate in this group was 1.1\%. Table 4 summarises the relevant data of these patients.

TABLE 4: Patients with recurrent chest pain requiring revascularisation

\begin{tabular}{|c|c|c|c|}
\hline Patient & $\begin{array}{l}\text { Presenting } \\
\text { symptom }\end{array}$ & Procedure & $\begin{array}{l}\text { Time after } \\
\text { MIBI (months) }\end{array}$ \\
\hline 1 & $\begin{array}{l}\text { Atypical } \\
\text { chest pain }\end{array}$ & Mitral valve replacement and CABG & 68 \\
\hline 2 & $\begin{array}{c}\text { Typical } \\
\text { chest pain }\end{array}$ & PTCA & I \\
\hline 3 & $\begin{array}{c}\text { Typical } \\
\text { chest pain }\end{array}$ & CABG & 49 \\
\hline 4 & $\begin{array}{l}\text { Atypical } \\
\text { chest pain }\end{array}$ & $C A B G$ & 15 \\
\hline 5 & $\begin{array}{l}\text { Atypical } \\
\text { chest pain }\end{array}$ & PTCA & 26 \\
\hline 6 & $\begin{array}{c}\text { Typical } \\
\text { chest pain }\end{array}$ & CABG & 23 \\
\hline
\end{tabular}

PTCA = percutaneous transluminal coronary angioplasty $C A B G=$ coronary artery bypass grafting
Revascularisation was performed at an average of 30 months ( 1 - 68 months) after the normal Tc-99m MIBI study. Only in one case (0.8\%) was revascularisation performed less than one year after the MIBI study. None of the 36 patients with partial follow-up had a secondary cardiac event during the period for which follow-up information was available.

Of the 14 patients referred for the Tc-99m MIBI study after coronary angiography, and in whom follow-up was complete, none developed any coronary events during a mean follow-up period of $55 \pm 11.5$ months (range 43 - 74 months), including 3 patients with significant stenoses in one or more coronary arteries, but who did not have a revascularisation procedure performed. These 3 patients had a high mean pre-test probability for coronary artery disease (90.4 $\pm 2.7 \%$ ) with a mean follow-up period of $62.7+17.2$ months.

Fourteen patients in whom follow-up information was either incomplete (8) or absent (6) had coronary angiography before the MIBI study. Two of these had significant coronary artery disease but had no revascularisation procedure performed. The follow-up periods were 48 and 45 months respectively. Both had a high pre-test probability for CAD (90.6\% each). As mentioned before, one died 71 months after the MIBI study.

Eleven of the 28 patients who had coronary angiography performed before the Tc-99m MIBI study, also had a revascularisation procedure (8 PTCA and 3 CABG) performed prior to the study. In 7 of these patients complete follow-up information could be obtained. No cardiac events were recorded in any of these. In 4 of the II patients, follow-up was incomplete. None of them developed any cardiac events during the period for which follow-up information could be obtained (mean $=27 \pm 17.1$ months). No deaths were registered for any of these 4 patients.

\section{Deaths}

Twelve patients (5.7\%) died during the follow-up period. In seven of these complete follow-up information was available. Two of these patients died of unknown causes. The cause of death was proved to be of a non-cardiac origin in the remaining 5 patients. One of the patients in whom the cause of death could not be ascertained suffered from chronic bronchitis and emphysema. This patient was referred for the Tc-99m MIBI study because of a mildly positive effort electrocardiogram (ECG). This patient died 36 months after the MIBI study. The other patient died $6 \mathrm{I}$ months after the MIBI study. This patient suffered from chronic rheumatic heart disease with involvement of all four valves.

No follow-up information, except for the fact that the death was registered as well as the cause of death as given on the death certificate, was available in 5 of the 12 patients. Two of these patients presumably 
died of cardiac causes (as discussed previously). The causes of death in the remaining 3 patients were given as carcinoma of the pancreas, bronchial carcinoma and intracerebral haemorrhage.

\section{DISCUSSION}

Myocardial perfusion scintigraphy with TI-20I is well established as an excellent modality not only to diagnose CAD, but also for risk stratification.Tc-99m-MIBI imaging is also being used for risk stratification. Numerous studies have reported on the prognostic significance of a normal exercise $\mathrm{MIBI}$ study, over a follow-up period of less than 3 years. ${ }^{(32-36)}$ These reports all confirmed the benign outcome in patients with a normal MIBI study over this follow-up period. Recently published reports have also demonstrated a good prognosis over even longer follow-up periods. ${ }^{(37-40)}$

The present study was performed to investigate the outcome in 209 patients with normalTc-99m MIBI studies over a mean follow-up period of 4.2 years. In 157 patients either complete or partial follow-up information could be obtained. No primary cardiac events were recorded in 121 patients with complete follow-up, while $4.9 \%$ developed secondary events during the follow-up period. The annual cardiac event rate in this group was $1.1 \%$. These results are comparable to those reported for normal TI-20I stress imaging and the same as those reported for normal Tc-99m MIBI studies.

A major limitation of our study was the fact that only partial follow-up information was available in 36 of the 209 patients and no follow-up information in 52. None of the group that was partially followed for a mean follow-up period of 2.7 years, developed any primary or secondary events during the period for which follow-up information was available. One of these patients subsequently died of a putative myocardial infarction, 7I months after the MIBI study. One patient from the group of 52 with no follow-up information died of ischemic heart disease, according to the death certificate. From this information it is likely that 2 of the 209 patients might have died from a fatal primary cardiac event, signifying a cardiac death rate of $0.96 \%$, confirming the low cardiac death rate reported in the literature in patients with normal MIBI or TI-20I studies.

It is impossible to report on the incidence of secondary cardiac events or non-fatal primary cardiac events in the group with no follow-up information or in the patients with only partial follow-up for the period after they were lost to follow-up. Our data, however, show that there was no statistically significant difference between these groups and the group in which follow-up could be completed regarding mean age, treadmill exercise parameters and the pre-test probability for coronary artery disease. Based on these findings, it could be argued that it would be highly unlikely that the incidence of cardiac events in these two groups would be significantly different from that found in the group in which follow-up could be completed. It has been reported that patients with a normal exercise thallium-20I study have a benign prognosis over a mean 2-year follow-up period even when angiographically significant coronary artery disease is present. ${ }^{(28)}$ This was confirmed for Tc-99m MIBI over a short- to medium-term follow-up period ${ }^{(32-34)}$ and over a longer follow-up period. ${ }^{(37-40)}$

Of the 28 patients in our study group who had coronary angiography before the MIBI study, only 5 had significant coronary artery disease, but no revascularisation procedures were performed. We are of the opinion that the small number of patients in this subset, as well as the subset of patients who had revascularisation performed prior to the $\mathrm{MIBI}$ study, is too small to allow any definitive conclusion to be drawn from the data.

The mean pre-test probability of coronary artery disease was moderate for this study group $(48+31 \%)$, indicating the lack of a selection bias towards a low-risk study population and increasing the significance of the finding of a low event rate amongst this group of patients with normalTc-99m MIBI studies. Calculation of the pre-test probability was based on the prevalence of CAD in the United States. ${ }^{(42)}$ The average age-standardised mortality rate from CAD amongst Whites, Asians and Coloureds in South Africa in 1989 was 29I per 100 000, compared to 235 in the USA in 1985. ${ }^{(45)}$ The mortality rate for South African Blacks was only 17 per 100 000. Our study population consisted mainly of Whites, Coloureds and Asians, with only one Black subject. It could be argued that the prevalence of CAD in our study group might be higher than in the USA, leading to the possibility that the pre-test probability might even be higher than that calculated using the American data.

The purpose of this study was to evaluate the longer term prognostic value of a normal Tc-99m MIBI SPECT myocardial perfusion study. We did not evaluate patients with abnormal studies and therefore cannot comment on the sensitivity of the test in our laboratory.

\section{CONCLUSION}

In our study, with a mean follow-up period of 4 years, a benign outcome was found in 209 patients with a normal Tc-99m MIBI exercise-rest SPECT study, including those with angiographically proven significant coronary artery disease or prior coronary revascularisation. Our data indicates that Tc-99m MIBI is comparable to TI-20I in this respect. 


\section{REFERENCES:}

I. Liu XI, Wang XB, Gao RL, Lu P,Wang YQ. Clinical evaluation of 99mTc-MIBI SPECT in the assessment of coronary artery disease. Nuclear Medicine Communications 1992; | 3:776-779.

2. Herbst CP, Theron H du T, Van Aswegen A, Kleynhans PHT, Otto AC, Minnaar PC. A Comparison of the clinical relevance of thallium-20I and technetium-99m methoxyisobutyl-isonitrile for the evaluation of myocardial blood flow. S Afr Med 1990;78:277-280

3. Kiat $H$, Maddahi J, Roy LT, et al. Comparison of technetium- 99 m methoxyisobuty isonitrile and thallium-20 I for evaluation of coronary artery disease by planar and tomographic methods. Am Heart | 1989: | 17:1-1 |

4. Wackers FJ, Berman DS, Maddahi J, et al. Technetium-99m hexakis 2-methoxyisobuty isonitrile: human biodistribution, dosimetry, safety, and preliminary comparison to thallium-20 I for myocardial perfusion imaging. | Nucl Med 1989:30:30 I-31 I.

5. Iskandrian AS, Heo J, Kong B, et al. Use of technetium-99m isonitrile (RP-30A) in assessing left ventricular perfusion and function at rest and during exercise in coronary artery disease, and comparison with coronary arteriography and exercise thallium-20 I SPECT imaging. Am J Cardiol 1989;64:270-275.

6. Kahn JK, McGhie I, Akers MS, et al. Quantitative rotational tomography with $20 \mathrm{ITI}$ and $99 \mathrm{mTc} 2$-methoxy-isobutyl-isonitrile. A direct comparison in normal individuals and patients with coronary artery disease. Circulation 1989;79: I 282-1293.

7. Taillefer R, Dupras G, Sporn V, et al. Myocardial perfusion imaging with a new radiotracer technetium-99m-hexamibi (methoxy isobutyl isonitrile): comparison with thallium-20 I imaging. Clin Nucl Med 1989; 14:89-96.

8. West DJ, Najm YC, Mistry R, Clarke SE, Fogelman I, Maisey MN. The localization of myocardial ischemia with technetium-99m methoxy isobutyl isonitrile and single photon emission computed tomography. Br J Radiol 1989;62:303-313.

9. Maddahi J, Kiat $\mathrm{H}$, van Train KF, et al. Myocardial perfusion imaging with technetium-99m sestamibi SPECT in the evaluation of coronary artery disease. Am J Cardiol 1990;66:55E$62 \mathrm{E}$.

10. Narahara KA, Villanueva-Meyer J, Thompson C], Brizendine M, Mena I. Comparison of thallium-20I and technetium-99m hexakis 2-methoxyisobutyl isonitrile single-photon emission computed tomography for estimating the extent of myocardial ischemia and infarction in coronary artery disease. Am J Cardiol 1990;66: 1438-1444.

1।. Taillefer R, Lambert R, Essiambre R, Phaneuf D, LeveilleT. Comparison between thallium201 , technetium-99m-sestamibi and technetium-99m-teboroxime planar myocardial perfusion imaging in detection of coronary artery disease. J Nucl Med 1992;33:1091. 1098

12. Maublant JC, Marcaggi $X$, Lusson JR, et al. Comparison between thallium-20I and technetium-99m methoxyisobutyl isonitrile defect size in single-photon emission computed tomography at rest, exercise and redistribution in coronary artery disease. Am J Cardiol 1992;69:183-187.

13. Watson DD, Smith WH, Beller GA, Vinson EL, Taillefer R. Blinded evaluation of planar technetium-99m-sestamibi myocardial perfusion studies. J Nucl Med 1992;33:668-675.

14. Solot G, Herman J, Merlo P, et al. Correlation of 99m-Tc-sestamibi SPECT with coronary angiography in general hospital practice. Nucl Med Commun 1993; | 4:23-29.

15. Brown KA. Prognostic value of thallium-20I myocardial perfusion imaging: a diagnostic tool comes of age. Circulation 1991;83:363-381.

16. Brown KA, Boucher CA, Okada RD, et al. Prognostic value of exercise thallium-20 I imaging in patients presenting for evaluation of chest pain.J Am Coll Cardiol 1983; 1:9941001

17. Staniloff HM, Forrester JS, Berman DS, Swan HJ. Prediction of death, myocardia infarction, and worsening chest pain using thallium scintigraphy and exercise electrocardiography. J Nucl Med 1986;27:| 842-1848.

18. Gill JB, Ruddy TD, Newell JB, Finkelstein DM, Strauss HW, Boucher CA. Prognostic importance of thallium uptake by the lungs during exercise in coronary artery disease. N Engl | Med 1987:3 17:| 486- 489.

19. Kaul S, Finkelstein DM, Homma S, Leavitt M, Okada RD, Boucher CA. Superiority of quantitative exercise thallium-20I variables in determining long-term prognosis in ambulatory patients with chest pain: a comparison with cardiac catheterization. J Am Coll Cardiol 1988; 12:25-34.

20. Fleg JL, Gerstenblith G, Sonderman AB, et al. Prevalence and prognostic significance of exercise-induced silent myocardial ischaemia detected by thallium scintigraphy and electrocardiography in asymptomatic volunteers. Circulation 1990;81:428-436.

21. Pamelia FX, Gibson RS, Watson DD, Craddock GB, Sirowathka J, Beller GA. Prognosis with chest pain and normal thallium-20 I exercise scintigrams. Am J Cardiol 1985;55:920926.

22. Wahl JM, Hakki AH, Iskandrian AS. Prognostic implications of normal exercise thallium201 images. Arch Intern Med 1985; 145:253-256.

23. Wackers FJ, Russo DJ, Russo D, Clements JP.Prognostic significance of normal quantitative planar thallium-20I stress scintigraphy in patients with chest pain. I Am Coll Cardiol 1985;6:27-30.
24. Bairey CN, Rozanski A. Maddahi J, Resser KJ, Berman DS. Exercise thallium-20I scintigraphy and prognosis in typical angina pectoris and negative exercise electrocardiography. Am J Cardiol 1989:64:282-287.

25. Koss JH; Kobren SM, Grunwald AM, Bodenheimer MM. Role of exercise thallium-20 I myocardial perfusion scintigraphy in predicting prognosis in suspected coronary artery disease. Am I Cardiol 1987:59:531-534.

26. Stratmann HG, Mark AL, Walter KE, Williams GA. Prognostic value of atrial pacing and thallium-20 I scintigraphy in patients with stable chest pain. Am J Cardiol 1989;64:985990.

27. Iskandrian AS, Hakki AH, Kane-Marsch S. Exercise thallium-20 I scintigraphy in men with nondiagnostic exercise electrocardiograms. Prognostic implications. Arch Intern Med 1986; 146:2189-2193.

28. Brown KA, Rowen M. Prognostic value of a normal exercise myocardial perfusion imaging study in patients with angiographically significant coronary artery disease. Am J Cardiol 1993;71:865-867.

29. Steinberg EH, Koss JH, Lee M, Grunwald AM, Bodenheimer MM. Prognostic significance from 10-year follow-up of a qualitatively normal planar exercise thallium test in suspected coronary artery disease. Am J Cardiol 1993:71: 1270- 1273.

30. Vanzetto G, Ormezzano O, Fagret D, Comet M, Denis B, Machecourt J. Long-term additive prognostic value of thallium-20I myocardial perfusion imaging over clinical and exercise stress test in low to intermediate risk patients: study in 1137 patients with 6year follow-up. Circulation 1999; 100: 1521 - I527.

31. Machecourt J, Longere P, Fagret D, et al. Prognostic value of thallium-20। single-photon emission computed tomographic myocardial perfusion imaging according to extent of myocardial defect. Study in 1,926 patients with follow-up at 33 months. J Am Coll Cardiol 1994:23: I096-I I06.

32. Brown KA, Altland E, Raven M. Prognostic value of normal technetium-99m-sestamibi cardiac imaging. J Nucl Med 1994:35:554-557.

33. Raiker K, Sinusas AJ, Wackers FJ, Zaret BL. One-year prognosis of patients with normal planar or single-photon emission computed tomographic technetium-99m-labeled sestamibi exercise imaging. J Nucl Cardiol 1994; I:449-456.

34. Berman DS, Kait H, Cohen J, et al. Prognosis of 1044 patients with normal exercise Tc99m-sestamibi myocardial perfusion SPECT. I Am Coll Cardiol 1994; Special Issue: 63A

35. Heller GV, Herman SD, Travin MI, Baron JI, Santos-Ocampo C, McClellan JR. Independent prognostic value of intravenous dipyridamole with technetium- $99 \mathrm{~m}$ sestamibi tomographic imaging in predicting cardiac events and cardiac-related hospital admissions. J Am Coll Cardiol 1995;26:1202-1208.

36. Geleiinse ML, Elhendy A, van Domburg RT, et al. Prognostic value of dobutamineatropine stress technetium-99m sestamibi perfusion scintigraphy in patients with chest pain. J Am Coll Cardiol 1996;28:447-454

37. Thomas GS, Miyamoto Ml, A. et al. Technetium99m Sestamibi myocardial perfusion imaging predicts clinical outcome in the community outpatient setting. The Nuclear utility in the community (NUC) study. Am Coll Cardiol 2004;43: 213-223.

38. Koehli M, Monbaron D, Prior JO., et al. SPECT myocardial perfusion imaging. Long-term prognostic value in diabetic patients with and without coronary artery disease. Nuklearmedizin 2006;45:74-81.

39. Johansen A, Hoilund-Carlsen PF, Vach W, et al. Prognostic value of myocardial perfusion imaging in patients with known or suspected stable angina pectoris: Evaluation in a setting in which myocardial perfusion imaging did not influence the choice of treatment. Clin Physiol Funct Imaging 2006;26:288-295

40. Elhendy A, Schinkel AF, van Domburg RT, et al. Prognostic value of exercise stress technetium-99m-tetrofosmin myocardial perfusion imaging in patients with normal baseline electrocardiograms. Am J Cardiol. 2006;98:585-90.

4I. Yang MF, Dou KF, Liu XJ, Yang YJ, He ZX. Prognostic value of normal exercise $99 \mathrm{mTC}$ sestamibi myocardial tomography in patients with angiographic coronary artery disease. Nucl Med Commun 2006;27:333-8.

42. Diamond GA, Forrester JS. Analysis of probability as an aid in the clinical diagnosis of coronary artery disease. N Engl J Med 1979;300: I 350- I358.

43. Douglas PS, Ginsburg GS. The evaluation of chest pain in women. N Engl J Med 1996;334:1311-1315.

44. ACC/AHA/SNM Policy statement. Standardization of cardiac tomographic imaging. Nucl Med 1992;33: 1434- | 435.

45. Walker AR, Adam A, Küstner HGV. Changes in total death rate and in ischaemic heart disease death rate in interethnic South African populations, 1978 - 1989. S Afr Med J 1993:83:602-605 